\title{
Tuberculosis of Breast: Case Report
}

\author{
Alawi $\mathbf{M}^{1}$, Harraz $\mathbf{M}^{2 *}$ and Adel $\mathbf{A}^{2}$ \\ ${ }^{1}$ King Abd El-Aziz General Hospital (KAAH), KSA \\ ${ }^{2}$ Department of Radiodiagnosis, Faculty of Medicine, Mansoura University, Egypt
}

Submission: March 09, 2018; Published: March 20, 2018

*Corresponding author: Mohammed Mohammed Harraz, Department of Radiodiagnosis, Faculty of Medicine, Mansoura University, Egypt, Tel: +2-01223275336/+2-050-2545556; Fax: +2-0402972914; Email: Harrazharraz@live.com

\begin{abstract}
Tuberculous mastitis is often considered a form of granulomatous mastitis due to Mycobacterium tuberculous infection of the breast. Tuberculous mastitis can mimic many other pathologies in both clinical presentation and on imaging. Isolated primary involvement of the breast is extremely rare. It estimated incidence is less than $0.1 \%$ of all breast lesions in Western countries and 3-4\% of all breast lesions in endemic countries. It typically affects young lactating multiparous women.
\end{abstract}

Keywords: Mammography; Tuberculosis; Ultrasonography; Mastitis; Calcification

\section{Introduction}

Tuberculosis (TB) is a significant health problem. It is more common in the developing parts of the world, but there has been an emergence and reemergence of TB in industrialized countries due, in part, to migration. Other causal factors include the appearance of drugresistant strains of Mycobacterium tuberculosis and increasing number of immunosuppressed patients [1]. HIV is among the main contributors to this increased frequency of TB [2]. Diabetes is also a very common risk factor and is associated with an approximately three times increased risk for contracting TB [3]. Because the clinical presentation of TB is vague and insidious, the diagnosis is often delayed. Clinical suspicion is the key to the early diagnosis and prompt management, as well as the prevention of the disease's spread. The lungs are the most commonly affected organs, but TB may affect any organ system in the body, including the breast, bone \& GIT. Breast imaging findings may simulate those of more common neoplastic and infectious diseases. Considering the difficulty of growing M. tuberculosis bacilli, imaging may play a crucial role for the diagnosis, treatment guidance, and follow-up of these patients [4]. Tuberculosis (TB) may present with highly variable imaging findings. The findings may vary from nonspecific mastitis to abscesses or solid focal lesions.

\section{Case Presentation}

33 year-old female presented herself with pain right breast and history of TB. On clinical examination, the patient had two masses in right breast. The patient was initially examined with mammography which showed asymmetric density at right lower inner quadrant. No pleomorphic microcalcification, architectural distortion or obvious masses (Figure $1 \& 2$ ). The routine complementary breast ultrasound was done with a high frequency $(8-10 \mathrm{MHz})$ linear array head, which showed two collections noted at 5 and 8-9 o'clock positions (Figure $3 \&$
4). Finally US-guided fine needle aspiration was done. Also pathological, bacteriological analysis, and polymerase chain reaction (PCR) were done to prove the tuberculous nature of their lesions.

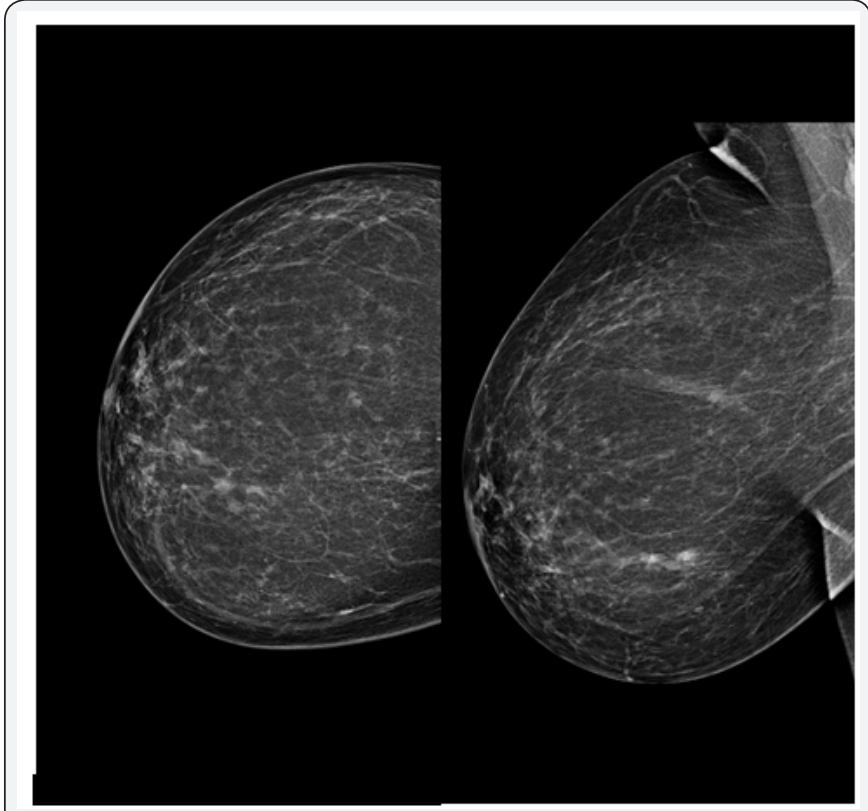

Figure $1 \&$ 2: Mammogram revealed asymmetric density at right lower inner quadrant. No pleomorphic microcalcification, architectural distortion or obvious masses. 


\section{Journal of Tumor Medicine \& Prevention}

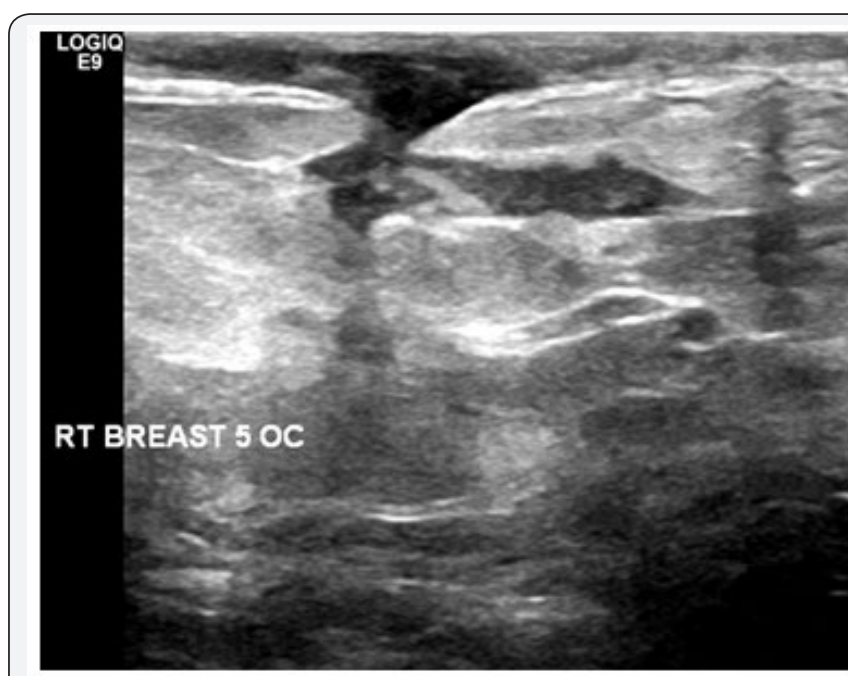

Figure 3: Ultrasonography revealed a collection noted at 5 o'clock position.

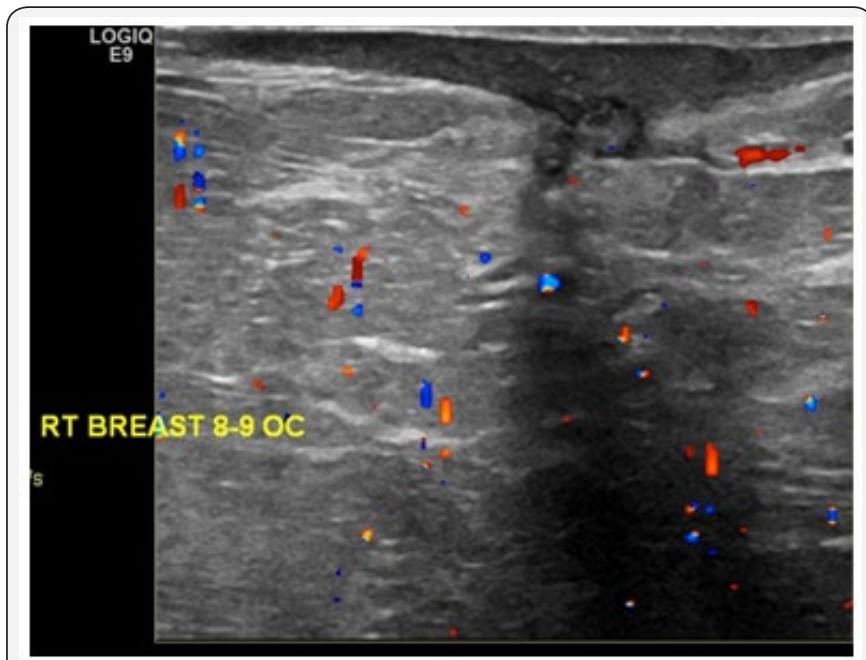

Figure 4: Ultrasonography revealed a collection noted at 8-9 o'clock position.

\section{Discussion}

TB breast can present with confusing imaging findings and make the diagnosis challenging. In addition to familiarity with the common imaging findings, medical history, patient demographics, and the patient's immune status should also be considered to reach a correct diagnosis [5].

In our case we do routine complementary ultrasonography with mammography and this agree with Stevenson et al. [3] stated that say ultrasound is generally the first modality used and can be helpful to screen the breast for potential solid \& cystic focal lesion detection, and edema. Contrast-enhanced CT may also provide valuable diagnostic clues and helpful in characterizing breast lesions, which may mimic breast macrogranuloma.

In our case ultrasonography finding are multiple collections and this agree with Adeiza et al. [6] stated that say lesions due to TB have no specific ultrasonographic findings. They may be heterogeneous, hypoechoic, irregularly bordered mass with internal echoes or thickwalled cystic lesions on ultrasonography. In some cases, there may be fistula formation and thickening of Cooper's ligaments and subcutaneous tissues [6]. MRI may be used in select cases when the sonographic or CT findings are inconclusive. CT may be skipped and an MRI study may be directly performed, especially if the breast abnormality is first detected on ultrasound, to save the patient from radiation exposure. MRI is more successful for delineating the internal structure of breast TB lesions, and the central liquefaction or abscess might be easier to detect, which may potentially affect the decision for treatment approach [5]

\section{Conclusion}

All cross-sectional imaging modalities, including sonography, CT, and MRI, may be used in the evaluation of patients with TB. Imaging findings may be perplexing to radiologists, particularly ones who practice in areas where TB is not endemic; thus, histopathologic diagnosis may be required.

\section{Ethical Approval}

Approval of the medical ethics committee was obtained for publication of this case report and accompanying images. The case was done in KAAH, KSA, ministry of health in October 2015.

\section{References}

1. Lee WK, VanTonder F, Tartaglia CJ, Dagia C, Cazzato RL, et al. (2011) CT appearances of abdominal tuberculosis. Clin Radiol 67(6): 596-604.

2. Lawn SD, Zumla AI (2011) Tuberculosis. Lancet 378(9785): 57-72.

3. Stevenson CR, Forouhi NG, Roglic G, Williams BG, Lauer JA, et al. (2007) Diabetes and tuberculosis: the impact of the diabetes epidemic on tuberculosis incidence. BMC Public Health 7: 234.

4. LoBue PA, Enarson DA, Thoen TC (2010) Tuberculosis in humans and its epidemiology, diagnosis and treatment in the United States. Int J Tuberc Lung Dis 14(10): 1226-1232.

5. Ködmön C, Hollo V, Huitric E, Amato-Gauci A, Manissero D (2010) Multidrug- and extensively drug-resistant tuberculosis: a persistent problem in European union and European economic area. Euro Surveill 15(11): 19519.

6. Adeiza MA, Yusuf R, Liman AA, Abur P, Bello F, et al. (2016) Tuberculosis of the breast: an initial presentation of the metabolic syndrome with type 2 diabetes mellitus in a young Nigerian woman. Case Rep Infect Dis 2016: 5485862 . 
This work is licensed under Creative Commons Attribution 4.0 License

DOI: 10.19080/JTMP.2018.02.555599
Your next submission with Juniper Publishers will reach you the below assets

- Quality Editorial service

- Swift Peer Review

- Reprints availability

- E-prints Service

- Manuscript Podcast for convenient understanding

- Global attainment for your research

- Manuscript accessibility in different formats

( Pdf, E-pub, Full Text, Audio)

- Unceasing customer service

Track the below URL for one-step submission https://juniperpublishers.com/online-submission.php 